\title{
Estimulação Essencial/ Intervenção Comunicativa e Atendimento Individualizado para Pessoas Surdas com Múltiplas Deficiências e Surdocegueira: Relato de Experiências em uma escola para Surdos
}

\author{
Estimulación esencial / intervención comunicativa y atención \\ individualizada para personas sordas con discapacidades múltiples y \\ sordoceguera: informe de experiencias en una escuela para sordos
Essential Stimulation / Communicative Intervention and Individualized Care for Deaf People with Multiple Disabilities and Deafblindness: Reporting Experiences at a Deaf School

Medeiros, Marta Cleonice M. Rosa, Alexsandra dos S. Escola Estadual de Educação Especial Dr. Reinaldo Fernando Cóser

\begin{abstract}
Resumo
O presente artigo parte de uma oficina apresentada na VI Semana Acadêmica do Curso de Pedagogia "Juntos Por Uma Universidade Pública, Inclusiva e de Qualidade", da Universidade Federal do Pampa, Campus Jaguarão/RS, 2019, e tem como objetivo fazer um breve relato sobre a criação da Escola de Educação Especial Dr. Reinaldo Fernando Cóser (escola para surdos), em Santa Maria/RS. Trata como surgiu a necessidade de se criar na escola as classes de Estimulação Essencial/ Intervenção Comunicativa e o Atendimento Individualizado para Pessoas Surdas com Múltiplas Deficiências, visando atender a demanda de alunos surdos que apresentavam outras deficiências associadas. Ao final, faz um relato da prática docente desenvolvida com uma aluna surdocega.
\end{abstract}

Palavras-chaves: Escola para Surdos. Relato de Prática. Surdocegueira.

\section{Resumen}

Este artículo es parte de un taller presentado en la VI Semana Académica del Curso de Pedagogía "Juntos por una Universidad Pública, Inclusiva y de Calidad", en la Universidad Federal de Pampa, Campus Jaguarão / RS, 2019, y tiene como objetivo realizar un breve informe sobre la creación de la Escuela de Educación Especial Dr. Reinaldo Fernando Cóser (escuela para sordos), en Santa Maria / RS. Se trata de la necesidad de crear las clases de Estimulación Esencial / Intervención Comunicativa y Servicio Individualizado para Personas Sordas con Discapacidades Múltiples en la escuela, con el objetivo de satisfacer la demanda de los estudiantes sordos que tenían otras discapacidades asociadas. Al final, da cuenta de la práctica docente desarrollada con un alumno sordociego.

Palabras clave: Escuela para Sordos. Informe de práctica. SORDERA.

\begin{abstract}
This article is part of a workshop presented at the VI Academic Week of the Pedagogy Course "Together for a Public, Inclusive and Quality University”, Federal University of Pampa, Campus Jaguarão / RS, 2019, and aims to make a brief report. about the creation of the Dr. Reinaldo Fernando Cóser Special Education School (school for the deaf), in Santa Maria / RS. It deals with the need to create in school the classes of Essential Stimulation / Communicative Intervention and Individualized Care for Deaf People with Multiple Disabilities, aiming to meet the demand of deaf students with other associated disabilities. At the end, she gives an account of the teaching practice developed with a deafblind student.
\end{abstract}

Keywords: School for the Deaf. Practice Report. Deafblindness. 


\section{Introdução}

O presente artigo trata de uma oficina apresentada na VI Semana Acadêmica do Curso de Pedagogia "Juntos Por Uma Universidade Pública, Inclusiva e de Qualidade", da Universidade Federal do Pampa, Campus Jaguarão/RS, 2019.

Neste texto, mostra-se o trabalho desenvolvido pela Escola de Educação Especial Dr. Reinaldo Fernando Cóser (escola para surdos), em relação aos seus alunos surdos que possuem outros comprometimentos associados a surdez, e que atualmente fazem parte do corpo discente da escola.

No decorrer do texto, fazemos um breve relato sobre a criação da escola no município de Santa Maria/RS, e como surgiu a necessidade de se criar as turmas de "Estimulação Essencial/ Intervenção Comunicativa e o Atendimento Individualizado para Pessoas Surdas com Múltiplas Deficiências", e o relato da prática docente desenvolvida com uma aluna surdocega.

A Escola Estadual de Educação Especial Dr. Reinaldo Fernando Cóser- escola para surdos, foi criada no dia 09 de Julho de 1998, pelo Decreto n ${ }^{\circ} 38.686$. E, Conforme ao Parecer CEE n 297/01, no dia 07 de Março de 2001, a escola obteve autorização para funcionar.

Em seu período inicial contemplava a Educação Infantil, Séries Iniciais e Finais do Ensino Fundamental. Sendo que no ano de 2005 a escola recebeu o parecer de autorização para o projeto Experimental de Curso Normal: 901/2005 de 21/12/05.

Atualmente conta com as seguintes modalidades de ensino: Estimulação Essencial; Projeto de Intervenção comunicativa e Atendimento Individualizado para pessoas Surdas com Múltiplas Deficiências; Educação Infantil; Ensino Fundamental - Anos Iniciais e Finais; Educação de Jovens e Adultos - Anos Iniciais e Finais; Projeto Experimental de Curso Normal; Curso Normal Aproveitamento de Estudos.

Sua implantação foi uma resposta ao apelo e anseio da comunidade surda que desejava que os surdos tivessem sua escolarização em um espaço educacional que fosse favorável à sua aprendizagem, onde pudessem ser respeitados dentro diferença linguística e cultural. Sendo assim, a Escola tem por finalidade, segundo o Regimento Escolar, 
garantir ao aluno surdo um ambiente linguístico adequado a fim de possibilitar-lhe o desenvolvimento de uma concepção de mundo; desenvolver no aluno surdo a sua integralidade, assegurando-lhe a formação comum, indispensável para o exercício da cidadania e fornecendo-lhe meios para progredir nos estudos posteriores; proporcionar aos alunos condições favoráveis à construção de um processo educacional que possibilite o desenvolvimento do cidadão analítico, reflexivo, crítico, capaz de transitar emocional e intelectualmente pela sociedade (2016, p. 05).

A Escola prima por uma abordagem Bilíngue como proposta na educação de seus alunos e como tal, a Língua de Sinais é trabalhada como primeira língua - L1 - dos surdos, e como segunda língua - L2 - a Língua Portuguesa, pois é a língua oficial de nosso país.

Trabalhar dentro desta proposta nos faz crer, que além de garantir o desenvolvimento da linguagem, ela promove que as pessoas surdas possam também construir e se apropriar de conceitos primordiais para a compreensão do mundo, uma vez que a escola oferece dentro desta abordagem, um espaço educacional linguístico e culturalmente adequado.

A oportunidade de acesso a um ambiente linguístico adequado deve ser proporcionada pela escola, tendo em vista quatro metas: Garantir o desenvolvimento da linguagem, do pensamento e do indivíduo. Para atingir essa meta, a escola deverá ser um ambiente em que a Língua de Sinais seja usada durante todo o período, isto é, a língua usada na escola é a Língua de Sinais; Assegurar o desenvolvimento da personalidade de forma sadia. Para isso, a criança precisa interagir com adultos surdos; Garantir que a criança surda construa uma teoria de mundo, (...). Quanto mais experiências de vida forem comentadas e elaboradas, amplia-se mais a concepção de mundo.(...); Assegurar o acesso aos conteúdos escolares. A Escola deve garantir ao aluno surdo todos os conteúdos que são estudados em uma escola de ouvintes (Plano Político Pedagógico, 2018, p. 11).

A escola também oferece aulas de Língua Brasileira de Sinais-LIBRAS (gratuitas) nas modalidades básico, intermediário e avançado, para os pais, professores, funcionários e comunidade em geral.

Dentro deste cenário, a nossa escola, também sentiu necessidade de criar uma classe de Estimulação Essencial/ Intervenção Comunicativa e Atendimento Individualizado para Pessoas Surdas com Múltiplas Deficiências, tendo em vista a procura de alguns pais por um atendimento diferenciado a seus filhos, pois esses apresentam quadro de surdez associada a uma ou mais deficiências, tais como: surdocegueira, surdez com paralisia cerebral, surdez com Síndrome de Down, surdez e autismo.

A turma de Estimulação Essencial/Intervenção Comunicativa - caracteriza-se por atender crianças surdas de 0 a 3 anos de idade e a turma de Atendimento Individualizado para Pessoas Surdas com Múltiplas Deficiências - atende crianças e/ou jovens a partir de 4 anos de idade. 
Surdos adultos que apresentem comprometimentos acentuados por falta de estímulos na tenra idade, também poderão participar deste projeto, "se necessário", no intuito de estimular as áreas em defasagem, procurando com isso, respeitar o aluno, dentro de suas características e individualidade. Essas turmas tem por objetivo,

Estimular a criança e/ou jovem nas áreas cognitivas, afetivas, social e comunicação em língua de sinais e língua de sinais tátil, proporcionando a construção da aprendizagem de maneira natural e lúdica; Caracterizar o atendimento pela prevenção e tratamento dos distúrbios no desenvolvimento, bem como suas potencialidades e formação de hábitos para independência e autonomia pessoal; Respeitar a individualidade e a dignidade da criança estabelecendo uma relação de confiança e carinho para que esse possa aprender a se comunicar; Orientar os pais quanto à estimulação em casa visando a continuidade do trabalho a fim de permitir um desenvolvimento integral de seu filho (Regimento Escolar, 2016, p. 11).

Conforme as necessidades apresentadas, os procedimentos de intervenção serão orientados de acordo com as individualidades e necessidades de cada aluno, oferecendo atividades que favoreçam o desenvolvimento integral desses sujeitos.

De acordo com o Regimento Escolar, os alunos que apresentam um quadro de surdez associada a uma ou mais deficiências, tais como: surdocegueira, surdez com paralisia cerebral, surdez com Síndrome de Down, surdez e autismo, surdez e Síndrome de Charge, entre outras terão aulas no Atendimento Individualizado para Pessoas Surdas com Múltiplas Deficiências. O Estatuto da Pessoa com Deficiência - Lei n ${ }^{\circ}$ 13.146/2015, em seu parágrafo único já diz: É dever do Estado, da família, da comunidade escolar e da sociedade assegurar educação de qualidade à pessoa com deficiência, colocando-a a salvo de toda forma de violência, negligência e discriminação. Cabe ressaltar que esses possuem um ritmo de desenvolvimento próprio.

Sendo assim, jovens/adultos que apresentem comprometimentos acentuados por falta de estímulos na tenra idade, também serão atendidos, "se necessário" nesse projeto, no intuito de estimular as áreas em defasagem, procurando com isso, respeitar o aluno, dentro de suas características e individualidade. Nestes casos os atendimentos são realizados de forma sistemática em sala de aula própria e de forma individualizada, possibilitando a estes alunos serem estimulados dentro de suas especificidades, levando-se em conta suas potencialidades e suas limitações. Este acompanhamento visa, além do atendimento da área pedagógica, dar suporte emocional aos nossos alunos, formando com ele um vínculo afetivo e emocional.

A avaliação é realizada através de reuniões semanais onde são discutidas e estudadas as teorias a fim de que sejam culminadas com a prática, levando-se em consideração a evolução de cada aluno nos aspectos: linguagem, cognição, percepção, socialização, 
afetividade e desenvolvimento motor. À medida que for observado que o aluno obteve avanços significativos em tais áreas, que lhe permita estar inserido em turma regular, o professor regente e equipe pedagógica farão esse encaminhamento.

\section{SURDOCEGUEIRA: Relato de prática}

Dentre os alunos que participam do Atendimento Individualizado para Pessoas Surdas com Múltiplas Deficiências, encontra-se uma aluna surdocega. A mãe relatou-nos que peregrinou por várias escolas da rede estadual e municipal e recebeu destas instituições negativas de matrícula, justificando falta de profissionais habilitados para trabalharem na área da surdocegueira.

Assim que soube da Escola Reinaldo F. Cóser tratou de ir conhecer e logo após a aluna foi matriculada. A aluna entrou na escola no ano de 2008, e contava com 7 anos de idade na época. Passou a ser atendida inicialmente na turma de Estimulação Essencial/Intervenção Comunicativa. Atualmente encontra-se na turma de Atendimento Individualizado para Pessoas Surdas com Múltiplas Deficiências.

A professora que trabalha com esta aluna possui formação em Educação Especial com Habilitação na área da surdez, Especialização em Educação Especial e Curso de Capacitação em Surdocegueira oferecido pelo Ministério da Educação e Cultura (MEC).

Falar de surdocegueira, é falar de uma deficiência singular que compromete tanto a visão quanto a audição. A pessoa surdocega apresenta perda visual e auditiva concomitante e em diferentes graus.

Conforme a organização (não governamental) Grupo Brasil de Apoio ao Surdocego e ao Múltiplo Deficiente Sensorial,

Surdocegueira é uma deficiência singular que apresenta perdas auditivas e visuais concomitantemente em diferentes graus, levando a pessoa com surdocegueira a desenvolver diferentes formas de comunicação para entender e interagir com as pessoas e o meio ambiente, para ter acesso a informações, uma vida social com qualidade, orientação, mobilidade, educação e trabalho. (GRUPO BRASIL, 2007 apud MAIA, 2011, p. 51). 
Segundo Ferioli (1993) apud Garcia (2008, p. 79): "a perda visual e auditiva não tem um efeito adicional sobre o desenvolvimento e a educação da criança Surdocega, mas sim um efeito multiplicador".

As causas da surdocegueira podem estar vinculadas a diversos fatores como: Infecções placentárias; Infecções pré-natais: AIDS, Herpes, Sífilis, Rubéola, Toxoplasmose, Citomegalovírus, Sífilis Congênita; Síndromes genéticas (Usher); Pós-natais: asfixia, meningite, encefalite, derrame cerebral, trauma craniano, otite média crônica, sarampo, caxumba, diabetes; Anomalias múltiplas congênitas: CHARGE.

Quanto ao tipo de perda: Surdez profunda associada com baixa visão; Surdez severa associada com baixa visão; Surdez moderada associada com baixa visão; Surdez moderada associada com cegueira; Surdocegueira total.

A surdocegueira pode ser congênita, ou seja, a pessoa nasce com a perda visual e auditiva ou pode ser adquirida, quando nasce sem a visão ou sem a audição e perde um desses sentidos ao longo da vida.

Classificação quanto ao período do surgimento:

Pré-Simbólica (Pré-linguística): quando o indivíduo nasce surdocego ou adquire a surdocegueira ainda bebê, antes da aquisição de uma língua, apresentando graves perdas visuais e auditivas combinadas.

Pós-Simbólica (Pós-linguística): quando o indivíduo apresenta uma deficiência sensorial (auditiva ou visual) e adquire a outra após a aquisição de uma língua (portuguesa ou de sinais), ou adquire a surdocegueira, após já comunicar-se por algum idioma, sem portar nenhuma deficiência anteriormente.

\section{Perfil da aluna}

Para preservar a identidade da aluna, ela será apresentada apenas com a inicial de seu nome: "M".

"M" apresenta surdez profunda bilateral associada com baixa visão. Nasceu com a retina aberta, fenda de palato e possui comprometimento motor. É Surdocega Pré-simbólica.

Apresenta movimentos estereotipados de dedos e mãos; balança o corpo ritmicamente; apresenta desinteresse em explorar objetos, brinquedos, pessoas e ambientes; é indiferente aos sons, sendo assim, não apresenta capacidade auditiva funcional para ouvir e interagir com o 
ambiente; apresenta distúrbios de alimentação; seus sentidos são usados apenas para sensações corporais; possui dificuldades em locomover-se; alimenta-se por sonda gástrica.

A mãe não sabe o motivo da surdocegueira da filha, relata ter tido uma gestação e parto tranquilos. Entretanto, ao analisar algumas características da aluna, a professora suspeita de que a causa da surdocegueira de "M" seja por Síndrome de CHARGE. Trata-se de uma síndrome causada por defeitos genéticos (WIKIPÉDIA, 2019). Já foram identificadas mais de 40 anomalias para esta síndrome, porém, as seis principais, formam o acróstico para as seis principais características, onde cada letra designa uma anomalia:

C - Coloboma do olho.

H - Defeitos cardíacos.

A - Atresia das coanas nasais.

$\mathbf{R}$ - Retardo no crescimento e/ou desenvolvimento.

G - Anormalidades genitais e/ou urinárias.

E - Anormalidades da orelha e surdez.

A mutação se dá no gene CHD7, o diagnóstico deve ser feito por um geneticista que tenha conhecimento sobre a síndrome, no entanto, nem sempre é possível detectá-la e por se tratar de um exame muito caro, o diagnóstico ainda é clínico e baseado nas características físicas.

"M" apresenta muito das características apresentadas na síndrome, por esse motivo, suspeita-se ser esta síndrome a causa de sua surdocegueira.

Por se tratar de uma deficiência com características singulares, a surdocegueira causa impactos significativos nas habilidades comunicativas, sociais e cognitivas.

A falta da estruturação da linguagem causadas pela concomitância da surdez e cegueira acabou por acarretar condutas inadequadas em "M", tais como: gritar; chorar, autoagridesse, pressiona os olhos com os dedos, morder-se, bate os pés.

É importante observar e atribuir significados a todas as formas de comunicação que a criança apresenta e que podem expressar suas necessidades. Choro, riso, apontar, dirigir o olhar para alguma coisa, podem ser formas de comunicação não intencional, mas que podem 
tornarem-se intencionais, na medida em que a pessoa mediadora dá um significado ao movimento.

\section{A comunicação}

Crianças com resíduo visual podem receber comunicação através da combinação de objetos, desenhos ou mesmo a Língua de Sinais, como também pode ser feita por meio de: Língua de Sinais Tátil; Método Tadoma; Expressões/Gestos Naturais; Alfabeto datilológico; Sistema Braille Tátil; Escrita na palma da mão (usar o dedo como lápis para escrever na palma da mão da pessoa surdocega); Objetos de referência.

Estratégias que apoiam a comunicação e o aprendizado: Rotinas (fundamental para o desenvolvimento da comunicação); Antecipação (ajuda a saber o que irá acontecer, a entender que pode ocorrer mudanças, a ter segurança emocional); Abordagem co-ativa (movimento mão sobre mão); Sistema de Calendários.

\section{A prática}

Logo que chegou à escola, "M" ficava na sala somente com a presença da mãe, pessoa na qual tinha maior vínculo. Sempre entrava chorando na sala e apresentava muita resistência ao toque de outras pessoas. Quando sentia que haviam mais pessoas na sala, agitava-se e chorava.

Apresentava comportamento hipoativo, não interessava-se em interagir e nem explorar objetos ou brinquedos (não atribuía função à nenhum brinquedo) ou mesmo pessoas. Se a colocássemos sentada em um determinado lugar, assim permanecia, apenas manifestando suas estereotipias, como sacudir as mãos ou balanceio do corpo.

Suas manifestações expressivas eram principalmente através de choro e isso geralmente acontecia quando se sentia incomodada com alguma coisa.

Com o objetivo de desenvolver uma comunicação e melhor interação com "M" primou-se por utilizar na prática pedagógica a abordagem co-ativa de Jan Van Dijk, que parte do simbólico para o concreto, que tem por objetivo favorecer o diálogo da criança com o mundo exterior.

Jan Van Dijk desenvolveu um programa de comunicação que baseia-se no movimento e compreende seis fases:

1) relação de apego (o vínculo afetivo é o primeiro passo para a comunicação e a linguagem); 2) fenômeno de ressonância (o adulto realiza movimentos junto à criança, corpo a corpo); 3) movimento co-ativo (as atividades são realizadas no sentido mão-sobre- mão); 4) 
referência não-representativa (introdução dos objetos de referência visando auxiliar no processo de identificação de pessoas, lugares e mesmo atividades; 5) imitação e 6) gestos naturais (ações, iniciativas das própria criança).

Segundo F. A. A. A. Cader-Nascimento e M. P. R. da Costa (p. 135, 2003):

A abordagem co-ativa de van Dijk (1968) apresenta procedimentos que podem possibilitar condições adequadas ao desenvolvimento da comunicação em surdocegos pré-lingüísticos. Esta abordagem parte do princípio que as atividades propostas precisam ser realizadas em conjunto com a criança, através do movimento de mão sobre mão. Para isto é fundamental o envolvimento afetivo dos participantes. A relação afetiva promoverá um ambiente no qual a criança sentir-se-á com uma margem de segurança para poder participar das atividades.

Algumas adaptações na sala foram necessárias para atender a aluna, como: Redução da claridade da sala com o uso de cortinas escuras e diminuição da luz das lâmpadas, pois apresenta sensibilidade excessiva à claridade (causado pelo coloboma ocular), faixa amarela na entrada na porta da sala, (para que pudesse identificá-la), tapetes e almofadas (pois não ficava muito tempo sentada na cadeira), espaço livre para locomoção (pois batia-se nos móveis).

Também optou-se por desenvolver um Calendário de Comunicação, que nada mais é que um sistema aberto, criado para favorecer a comunicação e dar oportunidade de compartilhar o mundo com a pessoa surdocega.

Os calendários são instrumentos que favorecem o desenvolvimento da noção de tempo e que ajudam os alunos a estabelecer e compreender rotinas. ( BOSCO; MESQUITA; MAIA, 2010).

O sistema de calendários é importante quando: é motivo para se comunicar; há associação de um símbolo com uma atividade, dá oportunidade para recusar ou pedir, permite à criança saber o que já aconteceu, bem como prever o que irá acontecer.

Ao utilizarmos o sistema de calendários ele nos ajudará a introduzir a noção de tempo marcando o início e o fim de cada atividade, além de favorecer a participação das pessoas com surdocegueira e/ou deficiências múltiplas sensorial no meio social no qual estão inseridas, fazendo uso de um sistema eficiente de comunicação. Possibilita também, planejar/organizar ações, lembrar/memória, antecipar eventos, avaliar.

Sendo assim, foram utilizados objetos de referência objetivando possibilitar a antecipação da atividade que a aluna iria desenvolver. $\mathrm{O}$ sistema de calendários proporciona a segurança de saber o que vai acontecer, favorecendo o desenvolvimento de uma relação de confiança. 
Para isso realizamos uma rotina de atividades diárias e para cada atividade foi inserido um objeto de referência, pois entende-se que estabelecer uma rotina proporcionará melhores condições para que a aluna consiga ter uma previsibilidade das atividades do seu dia a dia, o que irá acontecer, quais atividades irá fazer. Essa antecipação dos acontecimentos fará com que se sinta segura.

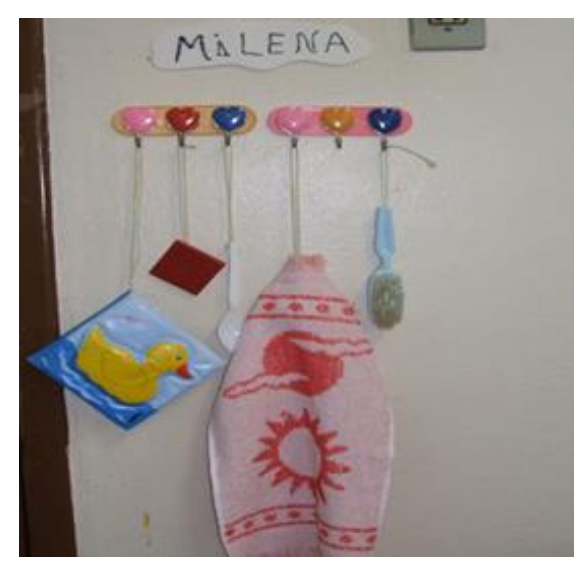

Figura 1 - Calendário com a rotina de "M”. Fonte: Material das pesquisadoras. (2018)

\section{Primeira Atividade:}

Recepção com estímulo prazeroso: sempre que vinha para a escola, M trazia em suas mãos um ralador de alimentos, ao contrário do que normalmente as crianças fazem, em levarem seus brinquedos preferidos à escola, M tinha predileção por raladores de legumes e que era de metal. Normalmente deitava seu rosto nas cerdas ásperas ou balançava-o frente ao rosto. A aluna sempre demonstrou preferência por objetos com texturas ásperas e se tentássemos retirar o objeto de suas mãos, chorava, gritava e mordia-se.

Sendo assim, ao chegar na sala com o objeto, M era conduzida até o calendário. Nele, a aluna era orientada a pendurar seu ralador (no calendário que ficava fixado à parede) e o trocávamos por um livrinho que a aluna gostava de manusear pois nele continham imagens em alto relevo. Seu ralador só era devolvido no final da aula após realizar todas as atividades estabelecidas na sua rotina e que eram antecipadas pelos objetos de referência. 
RELACult - Revista Latino-Americana de Estudos em Cultura e Sociedade

Revista Latinoamericana de Estudios en Cultura y Sociedad | Latin American Journal of Studies in Culture and Society V. 06, Edição Especial, out, 2020, artigo n ${ }^{\circ} 1900$ | claec.org/relacult | e-ISSN: 2525-7870

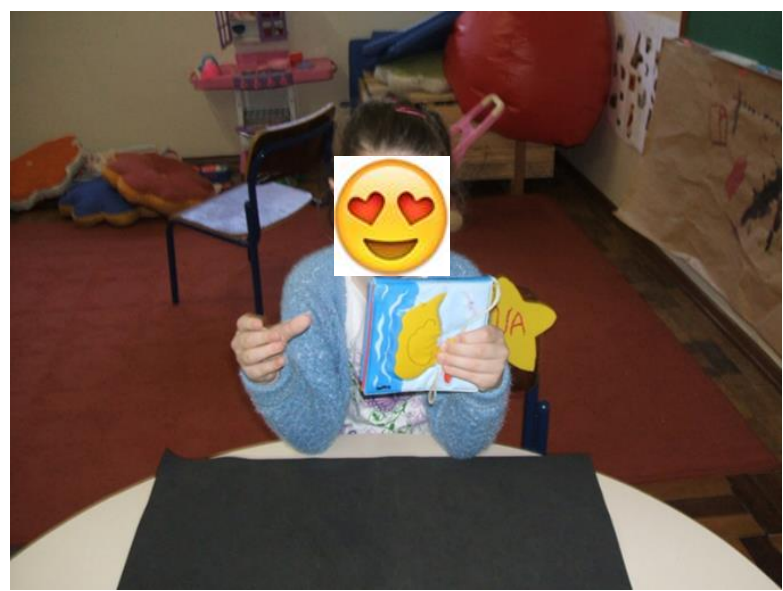

Figura 2 - Primeira atividade. Fonte: Material das pesquisadoras (2018).

\section{Segunda Atividade}

Atividades lúdico-pedagógicas: Neste momento "M" buscava o objeto de referência da atividade que era uma peça em madeira dos blocos lógicos. As atividade desenvolvidas neste momento procuravam estimular seus sentidos remanescentes (corporais, gustativos, olfativos, visual), assim como a motricidade fina e ampla, orientação espacial, sentidos táteis, entre outras, visando o desenvolvimento social, motor e perceptivo da alunas.
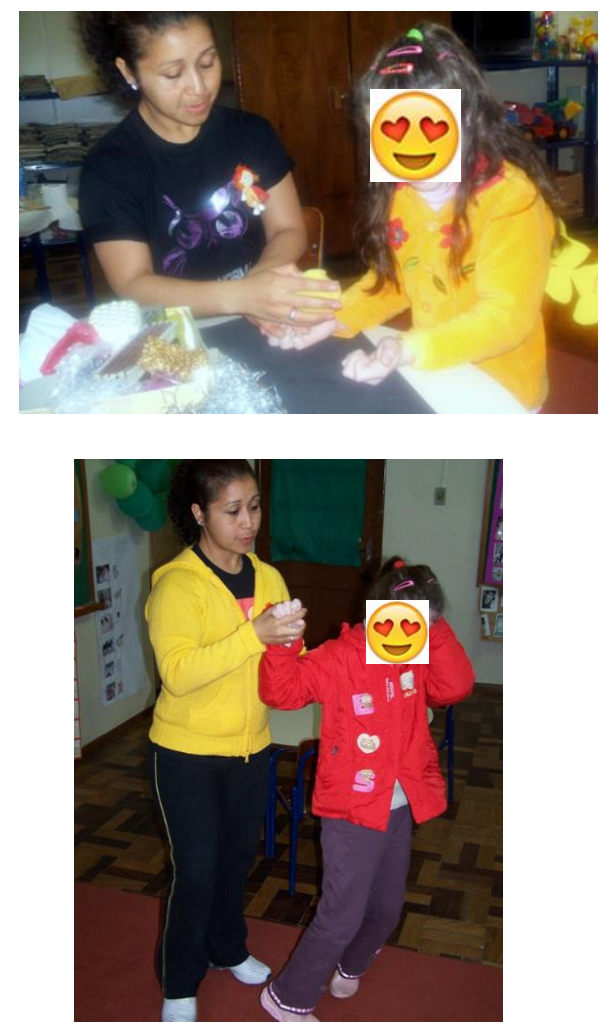

Figuras 3 e 4 - Estimulação Motricidade Ampla. Fonte: Material das pesquisadoras. (2018) 
Atividades de estimulação tátil objetivavam estimular a aluna a manipular os mais variados tipos de texturas, pois "M" apresentava defesa tátil.

A defesa tátil é a forma como a criança experimenta e reage de maneira negativa e emocionalmente às sensações do tato, segundo Ayres (1982) apud BOSCO; MESQUITA; MAIA (2010, pg.9).

Para algumas pessoas, esta sensibilidade excessiva, torna algumas experiências táteis desagradáveis ou mesmo dolorosas.

"M" não gostava de tocar em superfícies macias, nem manusear tecidos ou materiais moles. Abraços e beijos também não eram muito tolerados pela aluna, assim como apresentava muita resistência em tocar a água. Por esse motivo, as atividades de estimulação tátil, foram sendo inseridas gradativamente na rotina da aluna.

\section{Terceira Atividade}

Hora do Lanche: Para esta atividade o objeto de referência escolhido foi uma colher e esta atividade foi inserida ao calendário objetivando estimular a mastigação e a deglutição. "M" nasceu com fenda de palato, o que interferiu no momento da sua amamentação. M não mamou e mesmo após a cirurgia corretiva, desde bebê sua alimentação era exclusivamente via sonda gástrica. Aos poucos fomos inserindo alimentos pastosos, até chegarmos atualmente aos alimentos um pouco mais sólidos como frutas, arroz, feijão, sopas. Entretanto ainda apresenta dificuldade em ingerir líquidos (afoga-se) e carnes vermelhas (pela textura mais sólida).

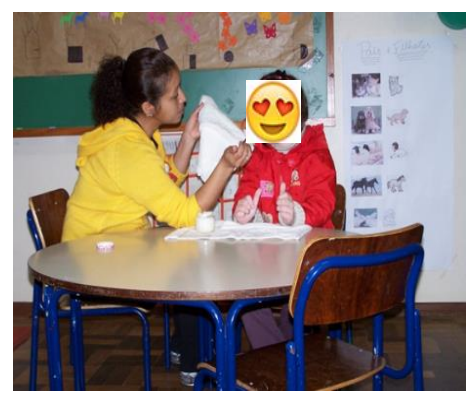

Figura 5 - Estimulação gustativa. Fonte: Material das pesquisadoras. (2018) 


\section{Quarta Atividade}

Hora da higiene: $\mathrm{O}$ objeto de referência escolhido para esta atividade foi uma toalha de rosto. Estimular hábitos de higiene foram fundamentais, uma vez que a aluna não permitia que seus familiares fizessem sua escovação dental, e não gostava de sentir a água no rosto e mãos. Esta atividade só foi possível através dos movimentos co-ativos.

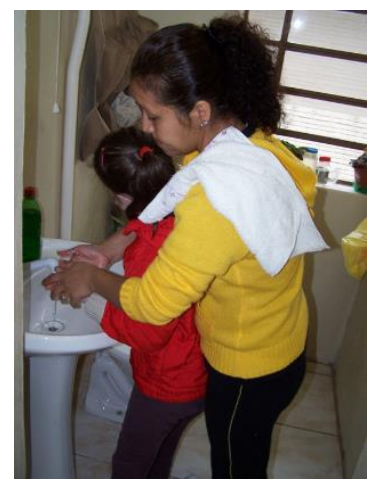

Figura 6 - Hábitos de higiene. Fonte: Material das pesquisadoras. (2018)

\section{Quinta Atividade}

Hora de ir para casa: Seu objeto de referência era uma escova de cabelos. Esta atividade foi escolhida porque a aluna começou a perceber que quando a professora arrumava seus cabelos era por que estava na hora e ir para casa. Automaticamente "M" pegava seu ralador e puxava a mão da professora para levá-la até a porta.

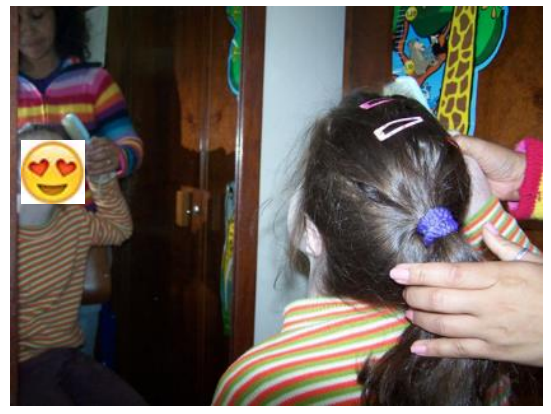

Figura 7 - Última atividade do calendário. Fonte: Material das pesquisadoras. (2018)

\section{Família Sujeito Ativo da Aprendizagem}

A família é fundamental neste processo, e como tal deve ser motivada a ser o agente transformador neste processo, compartilhando experiências e somando com os profissionais que trabalham com a criança surdocega. 
As informações trazidas pela família são importantes, e essas trocas de informações devem ser continua e diariamente especialmente no processo inicial de contato com o aluno. Dessa forma família e educador não se sentirão isolados (GARCIA, 2008). Será através destas informações que o professor conseguirá conhecer seu aluno e estudar formas de se aproximar e desenvolver uma prática que vá de encontro as necessidades deste.

É importante destacar que, mesmo que as respostas se apresentem a longo prazo, elas estão aí e são visíveis. Hoje, vê-se em "M" uma criança mais segura, mais independente, interativa e feliz. Uma criança que já começa apresentar uma melhora significativa na área social e comunicativa, fato observado não só nos momentos em que está na escola mas, também em seu meio familiar. Implementar ás suas atividades a abordagem metodológica de Van Dijk, principalmente a Coativa, foi ferramenta essencial no processo de desenvolvimento de "M".

\section{Considerações Finais}

Pretendeu-se neste trabalho, em forma de relato de experiências, proporcionar, de forma muito sintética, mas objetiva, uma familiarização com a nossa escola, que é referência do interior do estado do Rio Grande do Sul, por se tratar de uma escola para surdos e que trabalha também com o atendimento desenvolvido para os surdos com outros comprometimentos. Um desafio diário, para nós professores da área da educação de surdos, pois é necessário reinventar a própria docência diariamente, visto que estes alunos apresentam um tempo de resposta único e necessitamos proporcionar a construção da aprendizagem de maneira natural e lúdica de forma sistemática, respeitando as especificidades de cada aluno, considerando, também, suas potencialidades e limitações.

Atualmente, podemos evidenciar respostas aos estímulos trabalhados com essas turmas. Observa-se uma melhora significativa na área social e também comunicativa pois, já começam a apresentar indícios de comunicação receptiva e expressiva.

\section{Referencias}

BARROS, Célia Silva Guimarães. Psicologia e construtivismo. São Paulo: Ática, 1996.

BOTELHO, Paula. Segredos e Silêncios na Educação de Surdos. Belo Horizonte: Autêntica, 1998. 
BOSCO, Ismênia Carolina Mota Gomes. A Educação Especial na Perspectiva da Inclusão Escolar: surdocegueira e deficiência múltipla/Ismênia Carolina Gomes Bosco, Sandra Regina Stanziani Higino Mesquita, Shirley Rodrigues Maia. - Brasília: Ministério da Educação, Secretaria de Educação Especial: Fortaleza: Universidade Federal do Ceará, 2010. V.5 (Coleção A Educação Especial na Perspectiva da Inclusão Escolar).

BRASIL. Ministério da Educação. Lei n. 9.394, de 20 de dezembro de 1996: dispõe sobre as Diretrizes e Bases da Educação Nacional. Secretaria de Educação Profissional e Tecnológica.

Decreto n. 2.208, de 17 de abril de 1997. Dispõe sobre a regulamentação do parágrafo segundo do artigo 36 e os artigos 39 a42 da Lei Federal 9.394196 que estabelece as diretrizes e bases da educação nacional. Secretaria de Educação Profissional e Tecnológica. Leis e decretos.

Decreto $n .11 .741$, de 16 de junho de 2008: altera dispositivos da lei 9.394 de 20 de dezembro de 1996, que estabelece Diretrizes e Bases da Educação Nacional para redimensionar, institucionalizar e integrar as ações da educação profissional técnica de nível médio, da educação de jovens e adultos, e da educação profissional e tecnológica. Secretaria de Educação Profissional e Tecnológica. Leis e decretos.

CUNHA, Maria Jandyra. SANTOS, Percília (Orgs.). Ensino e pesquisa em português para estrangeiros. Brasília: Editora Universidade de Brasília, 1999.

DAVIS, Cláudia; OLIVEIRA, Zilma. Psicologia da educação. São Paulo: Cortez, 1994.

DORZIAT, Ana. Releitura da Surdez na Sociedade e suas implicações educacionais. Cadernos de Educação Especial, 1998.

Espaço - Informativo técnico científico do INES. Vols. V a X. Rio de Janeiro: INES, 1995, 1996, 1997, 1998.

F. A. A. A. CADER-NASCIMENTO E M. P. R. DA COSTA. A prática educacional com crianças surdocegas. Temas em Psicologia da SBP-2003, Vol. 11, no 2, 134- 146. Disponível em: http://pepsic.bvsalud.org/pdf/tp/v11n2/v11n2a07.pdf. Acesso em 14/11/2019.

FERREIRO, Emília. Alfabetização em processo. São Paulo: Cortez Editora, 1986.

FONSECA, Lúcia Lima. O universo da sala de aula - uma experiência em pedagogia de projetos. Vol. VII. Porto Alegre: Mediação, 1997.

FRANCO, Sérgio Roberto Hieling. O Construtivismo e a Educação. Porto Alegre: Mediação, 1998.

GARCIA, Alex. Surdocegueira Empírica e Cientifica. Rio Grande do Sul: editora Pessoa Física, 2008.

GARDNER, Howard. Inteligências múltiplas: a teoria na prática. Trad. Maria Adriana Veríssimo Veronese. Porto Alegre: Artes Médicas, 1995.

GÓES, Maria Cecília Rafael de. Linguagem, surdez e educação. 2 ed. Campinas, SP: Autores Associados, 1999.

LEFFA, Vilson J. Aspectos da leitura. Porto Alegre: Sagra - Luzzatto, 1996. 
MAIA, Shirley Rodrigues; ARAÓZ, Susana Maria Mana; IKONOMIDIS, Vula Maria. Surdocegueira e deficiência múltipla sensorial: sugestões de recursos acessíveis e estratégias de ensino. São Paulo: Grupo Brasil de Apoio ao Surdocego e ao Múltiplo Deficiente Sensorial, 2010

Descobrindo crianças com surdocegueira e deficiência múltipla sensorial, no brincar. 2011. 240f. Tese (Doutorado) - Universidade Presbiteriana Mackenzie. São Paulo, 2011.

MOLL, LUIS C. Vygotsky e a educação: implicações pedagógicas da psicologia sóciohistórica. Porto Alegre: Artes Médicas, 1996.

NASCIMENTO, Fátima Ali Abdalah Abdel Cader. Educação Educação Infantil: Saberes e Práticas da Inclusão: dificuldades de comunicação e sinalização: surdocegueira/múltipla deficiência sensorial. 4. ed. - Universidade Federal de São Carlos - UFSC/SP, prof. Shirley Rodrigues Maia - Associação Educacional para a Múltipla Deficiência - AHIMSA. Brasília: MEC, Secretaria de Educação Especial, 2006. 79 p.

\section{PROJETO POLÍTICO PEDAGÓGICO DA ESCOLA REINALDO FERNANDO CÓSER, 2018. Santa Maria, RS.}

QUADROS. R. M. de. Educação de Surdos: aquisição da linguagem. Porto Alegre: Artes Médicas, 1997.

\section{REGIMENTO ESCOLAR DA ESCOLA REINALDO FERNANDO CÓSER, 2016. Santa Maria, RS.}

REGO. Tereza Cristina. VYGOTSKY: uma perspectiva histórico-cultural da educação. Petrópolis, RJ: Vozes, 1995.

SKLIAR, Carlos (Org.). Atualidade da educação bilíngue para surdos - processos e projetos pedagógicos. Vols. I e II. Porto Alegre: Mediação, 1999.

. A Surdez: um olhar sobre as diferenças. Porto Alegre: Mediação 1997.

SOUZA, Regina Maria. Que palavra que te falta?: Linguística, educação e surdez. São Paulo: Martins Fontes, 1998.

TEBEROSKY, Ana; TOLCHINSKY, Liliana (Org.). Além da Alfabetização: a aprendizagem fonológica, ortográfica, textual e matemática. São Paulo: Ática, 1995.

VAN DIJK, J. (1968). Movimento e comunicação em crianças com rubéola. Tradução: (Dalva Rosa, Trad). Em Conferência na Reunião Geral Anual da Organização Nacional de Cegos da Espanha. São Paulo: AHIMSA.

VYGOTSKY, Lev Semenovictch. Pensamento e linguagem. São Paulo: Martins Fontes, 1993. 